SOCIETY AS A LEARNING SYSTEM:

DISCOVERY, INVENTION, AND INNOVATION CYCLES REVISITED

Cesare Marchetti

International Institute for Applied Systems Analysis, Austria

RR-81-29

November 1981

Reprinted from Technological Forecasting and Social Change, volume 18 (1980)

INTERNATIONAL INSTITUTE FOR APPLIED SYSTEMS ANALYSIS

Laxenburg, Austria 
Research Reports, which record research conducted at IIASA, are independently reviewed before publication. However, the views and opinions they express are not necessarily those of the Institute or the National Member Organizations that support it.

Reprinted with permission from Technological Forecasting and Social Change 18:267-282 (1980).

Copyright @ 1981 Cesare Marchetti.

All rights reserved. No part of this publication may be reproduced or transmitted in any form or by any means, electronic or mechanical, including photocopy, recording, or any information storage or retrieval system, without permission in writing from the copyright holder. 


\section{FOREWORD}

Early in its work the Energy Systems Program at the International Institute for Applied Systems Analysis recognized that one of the important controlling factors in changing the mix of technologies in the world's energy system was the rate at which a new technology substitutes for older ones, or, to put it differently, how long it will take a new technology to achieve a significant market penetration.

In a series of important papers, Cesare Marchetti showed that over the last century energy technologies had exhibited remarkably stable market-penetration properties, a fact that became an important building block in the IIASA analysis of the world's energy future over the next 50 years.

These results suggested that the form of stability exhibited by energy technologies could also be found elsewhere, and this paper explores this possibility for discovery, invention, and innovation cycles. Its findings show us that we have much to learn about these social processes that will be important to our efforts to shape our future effectively.

WOLF HÄFELE Leader

Energy Systems Program 


\title{
Society as a Learning System: Discovery, Invention, and Innovation Cycles Revisited
}

\author{
CESARE MARCHETTI
}

\section{ABSTRACT}

The very simple heuristic suggestion that society as a whole and its numerous subsets operate like learning systems, basically governed by Volterra-Lotka equations, has been extremely valuable in organizing a most variegated collection of statistical sets of time series, ranging from the structure of energy markets to the efficiency of machinery and the expansion of empires. In this paper an attempt is made to treat invention and entrepreneurship, generally perceived as the most "free" of human activities but actually subject to iron rules. Invention and innovation during the last 250 years appear in precisely structured waves that lend themselves to robust prediction. The present wave will reach its maximum momentum around 1990. Furthermore, the introduction, maximum market penetrations, and prices of new primary energies show a very strong link to these innovation waves. This stresses once more that economic features may be the expression of deeper "physical" phenomena related to the basic working of society and thus become predictable up to a point through a very abstract and noneconomic analysis.

This work has been done in the frame of IIASA's Energy Systems Program and can be considered as an outgrowth of and complement to the research on the evolution of energy systems described in IIASA Research Reports $79-12,79-13$, and 77-22. There it was found that a new primary energy coming into the market must be observed for 10 or 20 years if one is to extract the basic features necessary to predict its long-term market behavior. Specifically, it was concluded that the dates at which new primary energies come into play cannot be predicted. In this paper innovations are considered not one by one but as an abstract set, whose behavior is analyzed. In this frame possible birth dates for new energy sources can be identified, thus enhancing the quality of very long-term forecasting in the energy field. Also, prices appear predictable, at least in their gross features.

\section{Introduction}

The success of logistic market penetration analysis in describing the long-term behavior of energy markets and submarkets [1] stimulated an effort in theoretical research in order to reduce the empirically efficient logistic relationship to more basic and already accepted scientific axioms. A remarkable effort was made by Peterka [2], who was able to demonstrate that under constant productivity differentials competing industries win and lose the market following logistic paths.

Fleck [3] considers market penetration as a diffusion process in which the buyer is a scattering element in a Markov chain. From the properties of this microelement Fleck reconstructs the macroscopic behavior. This is an interesting reduction, although the properties of the microelement cannot yet be established a priori, and consequently the parameters of the logistic equation cannot be calculated before the penetration process starts. Fleck still limits his consideration to man as an economic animal.

CESARE MARCHETTI is associated with the International Institute for Applied System Analysis (IIASA), Laxenburg, Austria. This paper was invited for presentation at a meeting on Marketing and Product Innovation Facing Social and Technological Change organized by the Italian Association for Marketing Studies (AISM) in Turin, 18-19 April, 1980. 
I would like to go one step further toward abstraction and simplicity and assume that society is a learning system, that learning is basically a random search with filters, and that random searches are characterized by logistic functions $[4,5]$. The most natural way to proceed is through examples of increasing complexity. Abstraction is then possible and some deductions can be drawn.

The first and most important link in all human chains and feedback loops is man. It can be interesting to see him at work, for example, as a child trying to appropriate and get command of an intricate structure like that of a language. As a monitor of progress I chose the growth of the child's vocabulary. The result is given in Figure 1, where the curve is fit to a function of the form $\log (F / 1-F)=a t+b$ and $F$ is a measure of the number of words the child can command: the fraction of a vocabulary for current use of about 2500 words.

My second example concerns a group of people interconnected by informational links, much as scholarly journals, and working on a common task, say pounding molecules to pieces in order to separate the unbreakable components, the stable atoms. That game drove the chemists crazy in the period $1750-1850$, roughly, when about 50

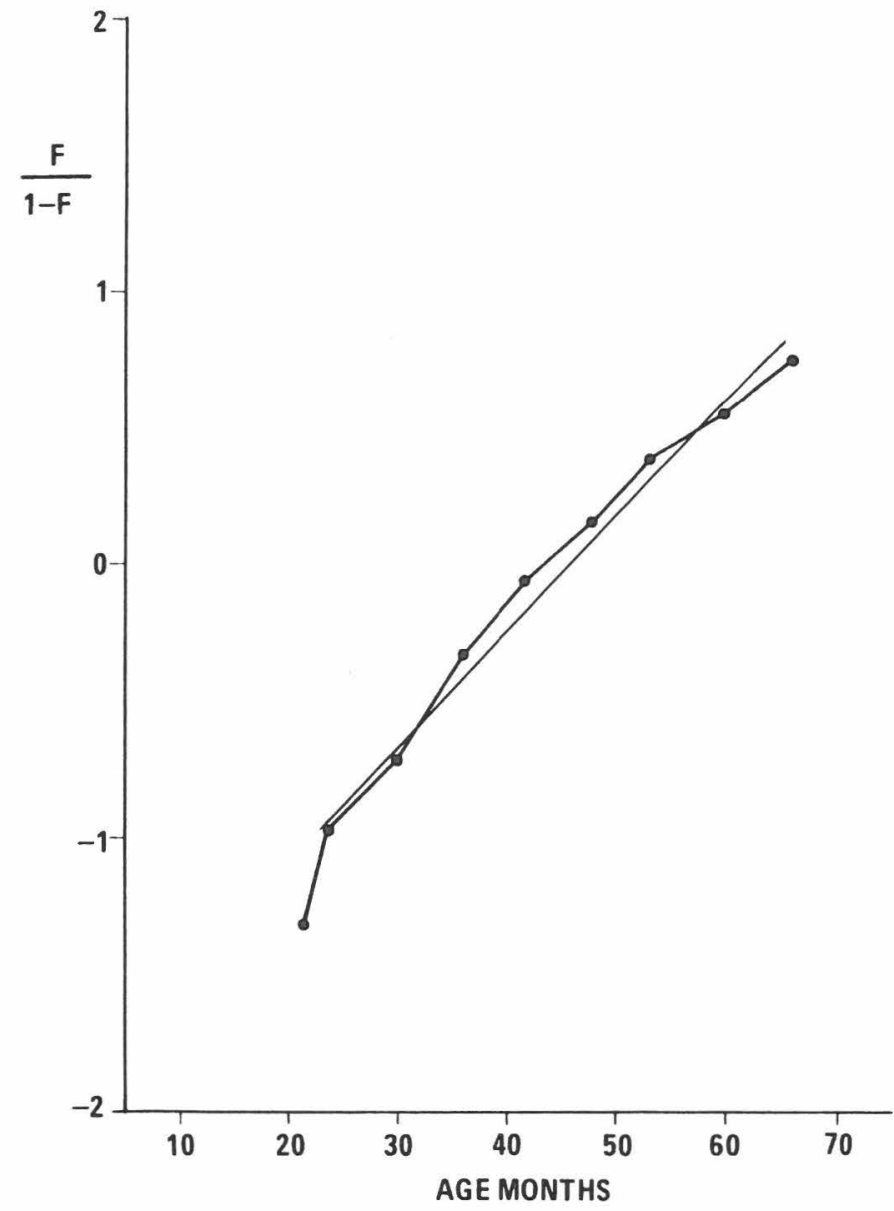

Fig. 1. Evolution of the vocabulary of a child. The final set of words used in current language is about 2500 words. $F(t)$ is the fraction of that set under control at time $t$. Source: Whiston [6]. 
stable elements were discovered. In Figure 2 the glorious progress is reported. The child and the learned guild seem to behave the same way, or at least the same functional relationship takes care of the two cases.

The third example bears some similarity to the second, except that the objects to be reached do not have a physical existence in the sense of words or chemical elements but belong to conceptual sets, like the set of ideas in the Platonic scheme. In Figure 3 the evolutionary trends of three technologies, embodied in machines of evolving performance, are reported. In a sense inventors, wandering in the world of all possible machines, picked those that looked best, ready to throw them away for the better ones as they appear, like Alice in Wonderland with her flowers. Here only one parameter, but a very important and subtle one, was taken as an indicator of performance: thermodynamic efficiency. This efficiency $\epsilon$ is plotted as ratio of $\epsilon / 1-\epsilon$, efficiency over inefficiency, and the data are fitted with a logistic equation.

Inventors are not organized in a guild, and their stimulus and financing come from a wide variety of sources. They are, however, interconnected by a literature and through

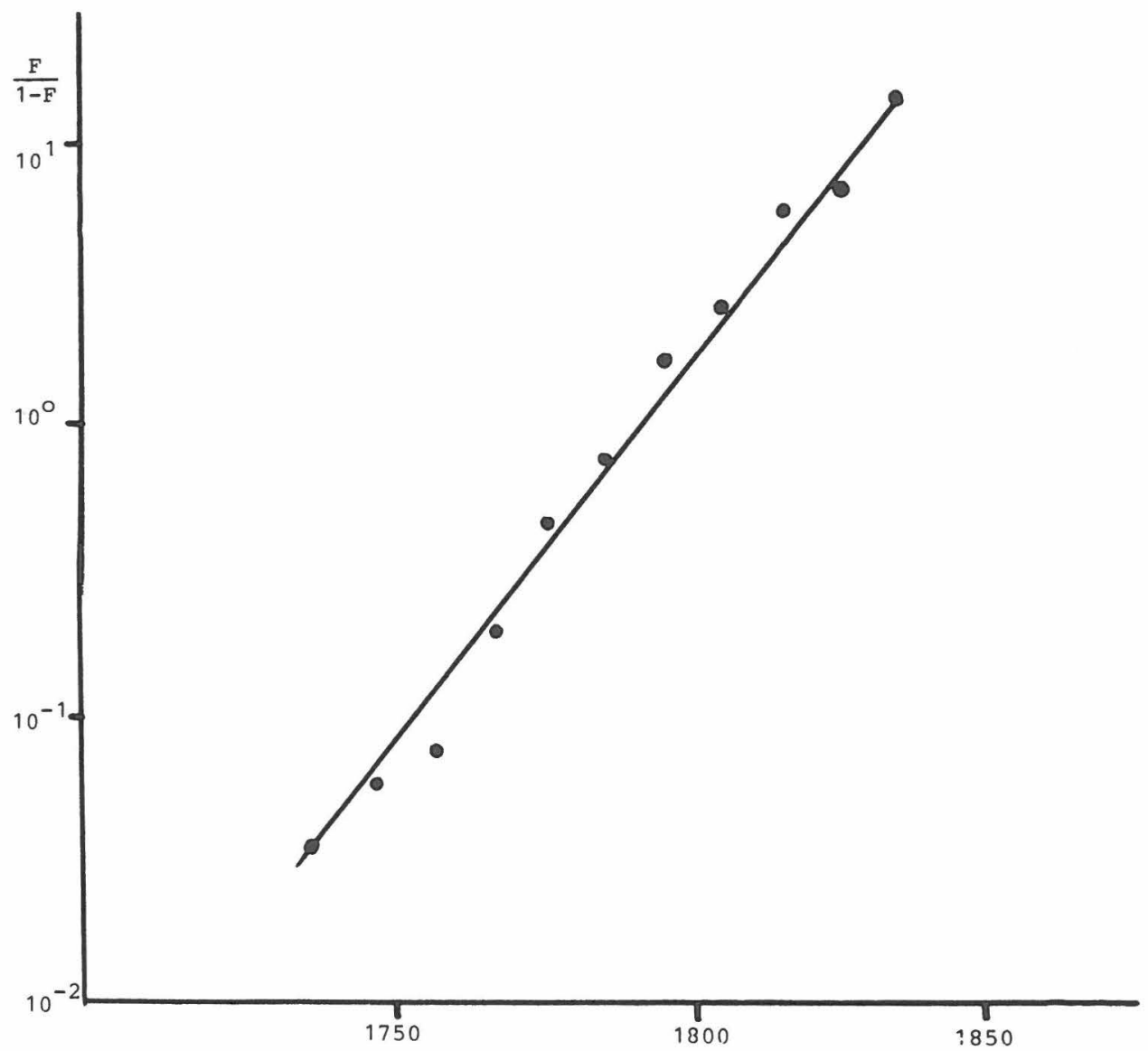

Fig. 2. The set of about $\mathbf{5 0}$ stable chemical elements that were discovered in the period under scrutiny can be defined as the elements accessible with current chemical technology. This defines the task and the means. $F(t)$ is the fraction of this set already discovered at time $t$. Source: The World Almanic [7]. 


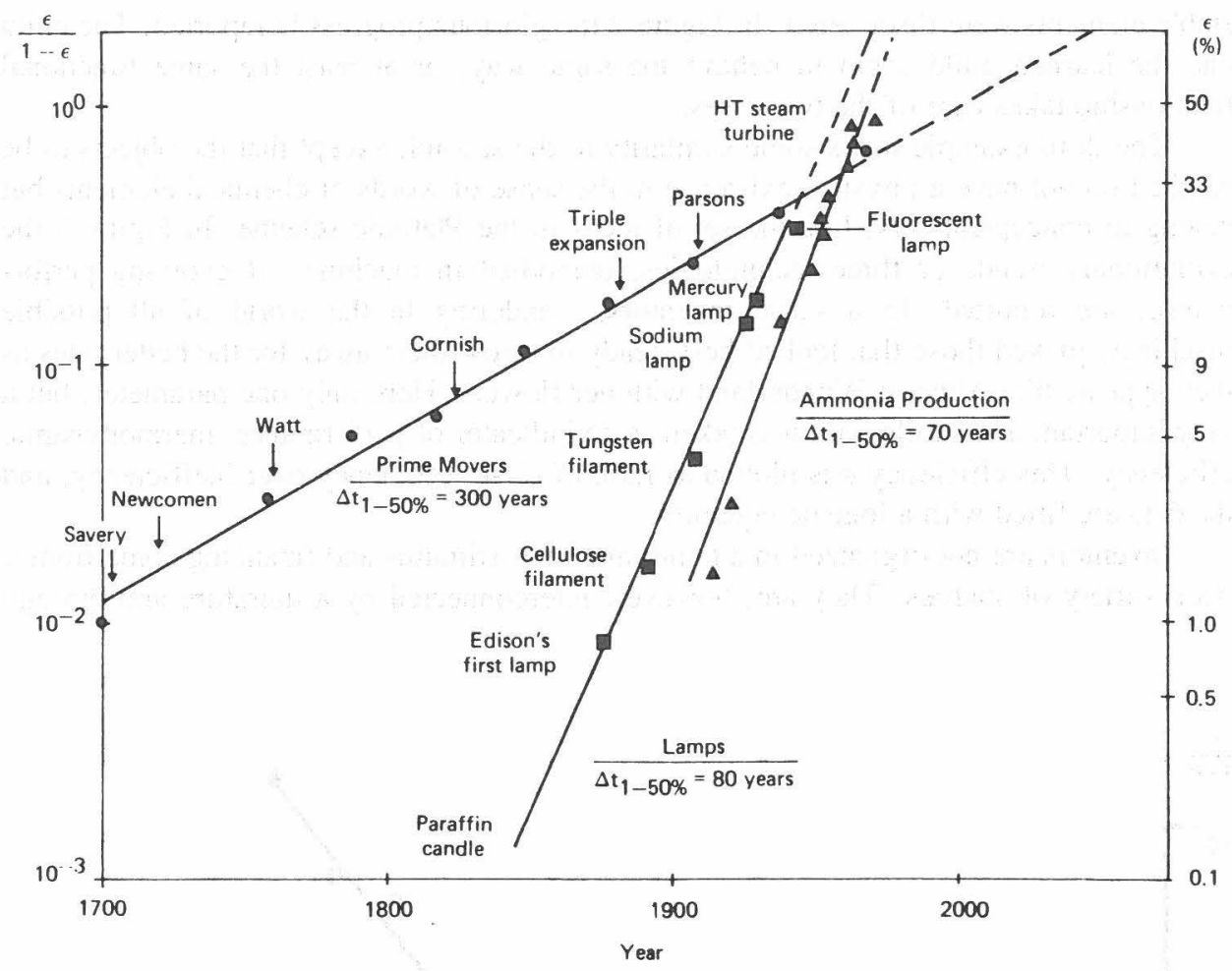

Fig. 3. The evolution of efficiency here given by reporting the efficiency of the best commercial machine at a given time. This efficiency is referred to the maximum possible thermodynamically. Consequently steam engines efficiency refers not to Carnot but to free energy in the fuel. The time constant $\Delta t$ represents the slope given as the time to go from $10^{-2}$ to $10^{\circ}$ (1\% to $50 \%$ efficiency). This figure, reporting efficiency/inefficiency, I christened 'the Yang-Ying plot." Source: Marchetti [8].

inspection of competing products, and they seem to behave like a single structure, operating toward its purpose and insensitive to historical trivialities, like wars, pestilences, and economic crises.

The fourth example is of large industries capillarily interconnected to many strata of society-technical, economic, financial, and political-and drawing stimuli and constraints from them. Because the elements are industries, I again took thermodynamic efficiency as an indicator. As the statistical data show (Figure 4), the evolutionary pattern is exactly the same as before. Here, however, because of the visibility of the objects and their strong coupling, a war may be felt, perhaps bombing or a shortage of new equipment, as in the case of the British steel industry. It is remarkable, however, that some kind of internal clock keeps ticking, and finally the time lost is recovered in a well adjusted dash. This elastic reabsorption of perturbations is a general and surprising feature of practically all the systems studied.

The last example of the series (Figure 5) involves humanity as a whole and its behavior with respect to a very important item, the use of primary energy sources during the last century or so [1]. As can be seen, the fit of the statistical data and to the logistic curve is very snug over this very long period of time. Humanity, too, seems to behave like an interconnected system learning toward an objective at an extremely stable rate. Inciden- 


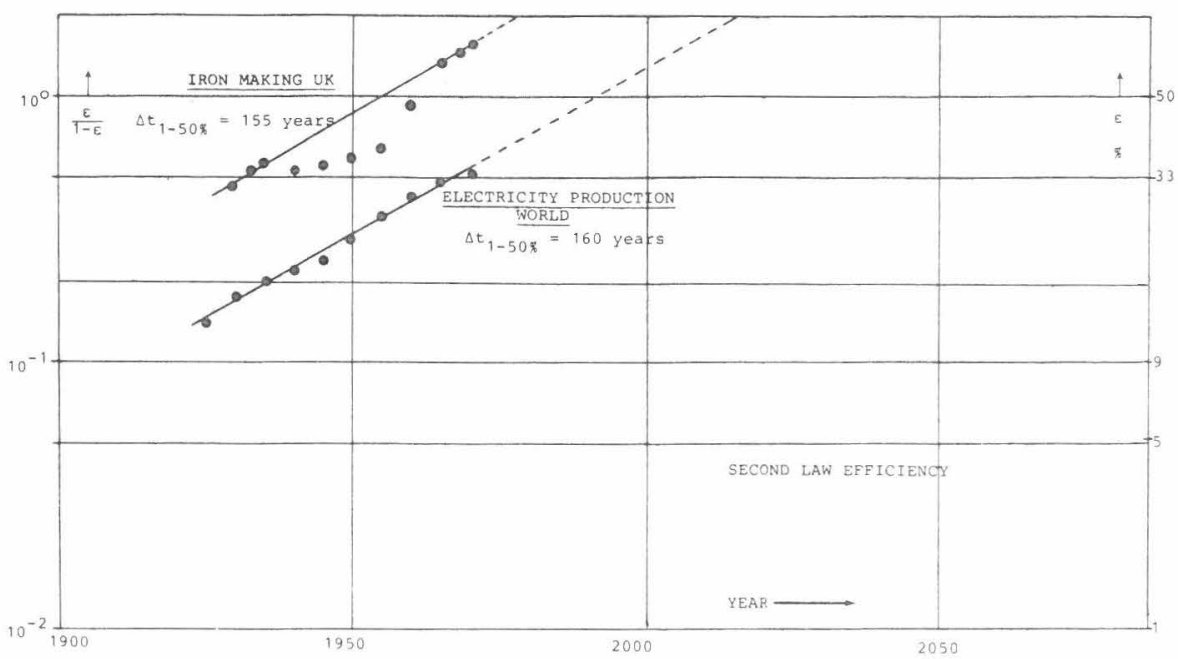

Fig. 4. Historical trends in efficiency, plotted much as Figure 3. The efficiency for electricity production is defined as the electrical energy/fuel energy. The assumption for fossil fuels that free energy and enthalpy of combustion coincide is adequate. With nuclear energy the definition should perhaps be revised. Source: Marchetti [8].

tally, the concepts of prices and resources do not appear necessary to describe the system. Prices appear contextual to the working of deeper physical mechanisms.

Armed with the working hypothesis that all sorts of societal subsets may operate in this way, I revisited a stimulating collection of data $[10,11]$ referring to waves of innovation in world industry during the last couple of hundred years (Figure 6).

$$
F /(i-F)
$$

FRACTION (F)

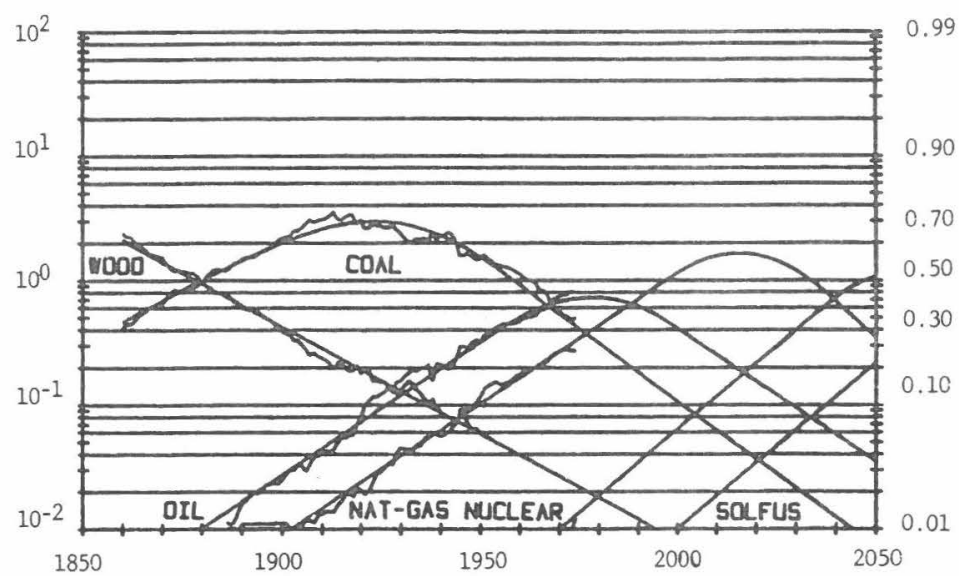

Fig. 5. World fractional energy substitution. $F$ is here the fraction of the market, defined in energy units (e.g., tons coal equivalent) taken by each primary energy at any time. The wriggling lines represent statistical data. Nuclear fuel has not yet much penetrated, and consequently the slope is hypothetical. Solar and fusion energy (SOLFUS) are hypothetical for both slope and initiation point. Source: Marchetti $[1,9]$. 


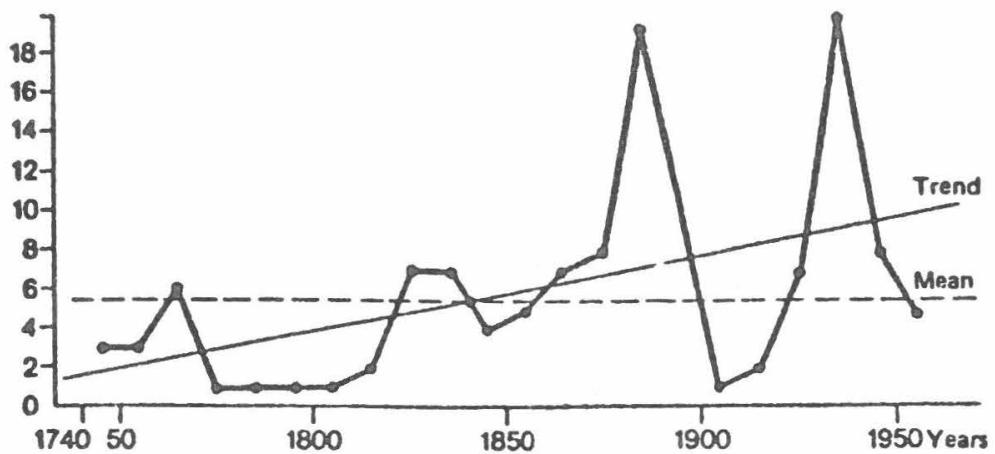

Fig. 6. Frequency of basic innovations, 1740-1960. The numbers of basic innovations reported here are given in 10 years bunches. Basic innovation is what gives rise to a brand new industry. Source: Mensch [10].

Contrary to current perception, innovations do not trickle from science to technology to industry, with a lag that keeps decreasing in time. Historical analysis shows that they come in season, like cherries. Some time later the cherry tree is reduced to a mere bunch of branches, ready to sprout, blossom, and produce for the next round.

For the analysis of the first wave (Figure 7 and Table 2), the data are taken from Mensch [10], who also quotes other sets assembled by other authors, claiming they do not differ substantially. The inventions and innovations belonging to this set are listed in Table 1. Innovation-or basic innovation, if we go to finer distinctions-is defined as something that starts a new industry. The grammophone, to give an example, is a (basic) innovation. Improvements in the process of manufacturing or in the quality of the products, which in the current language are also called innovations, are not considered here. Inventions refer to the discoveries that are at the base of the innovations. The two sets have been matched in the sense that inventions that did not develop into innovations are not listed.

TABLE 1

Invention and Innovation Cycles

\begin{tabular}{|c|c|c|c|c|c|c|c|}
\hline Innovations center point & 1828 & & 1880 & & 1937 & & (1992) \\
\hline Inventions center point & 1775 & & 1833 & & 1905 & & (1968) \\
\hline Midpoint of the cycle & 1802 & & 1857 & & 1921 & & $(1980)$ \\
\hline \multicolumn{8}{|l|}{$\Delta t$ between invention and } \\
\hline Innovation time constant & & $47 y$ & & $33 y$ & & $23 y$ & \\
\hline Invention time constant & & $120 \mathrm{y}$ & & $85 y$ & & $55 y$ & \\
\hline$\Delta t$ between innovation centers & & $53 y$ & & $57 y$ & & $(55 y)$ & \\
\hline$\Delta t$ between invention centers & & $58 y$ & & $72 y$ & & $(63 y)$ & \\
\hline$\Delta t$ between midpoints & & $55 y$ & & $63 y$ & & $(59 y)$ & \\
\hline \multicolumn{8}{|l|}{ Saturation of market penetration } \\
\hline for primary energies & $\sim 1800$ & & $\sim 1860$ & & 1921 & & 1980 \\
\hline & $\begin{array}{l}\text { Wood } \\
\text { (U.S.) }\end{array}$ & & $\begin{array}{l}\text { Hay } \\
\text { for } \\
\text { Animal } \\
\text { Power } \\
\text { (U.S.) }\end{array}$ & & $\begin{array}{l}\text { Coal } \\
\text { (World) }\end{array}$ & & $\begin{array}{l}\text { Oil } \\
\text { (World) }\end{array}$ \\
\hline
\end{tabular}


As my phenomenological analysis will be made in relative terms, the completeness of the sets is not important provided the selection of the cases is reasonably random. On the other hand, my prejudices could not influence the choice of data, which was made by Mensch.

The analysis of the first wave is reported in Figure 7 and Table 2. There the cumulative number $F$ of inventions and innovations is reported, normalized over the total set in the wave. The ordinates are the usual ones, to make the logistic behavior optically evident. The curves are characterized by their middle points, the dates when $50 \%$ of the inventions or innovations were made, and the time constants, measured in years elapsed between two decades in the ordinate. It is a meaningful way to measure slope. A piece of one of the curves of Figure 5 about primary energies substitution is superposed, following a suggestion by Graham and Senge [11] that innovation cycles and primary energy cycles may be interconnected.

Because of the number of elements in a set is quite limited, the fitting curves should be cut off below $F=5 \%$ and above $F=95 \%$ or so. The graphs, however, are often prolonged to $F=1 \%$ in order to show some interesting links to the energy cycles. The middle point between the central dates is also of significance in this connection. I will also use it to characterize the wave: 1802 thus locates the first wave.

Mensch made the interesting observation that the two sets are basically similar, that is, ordered. In other words, inventions go into innovations following the rule "first come, first served." Consequently, one can predict the date of the innovation if the invention can

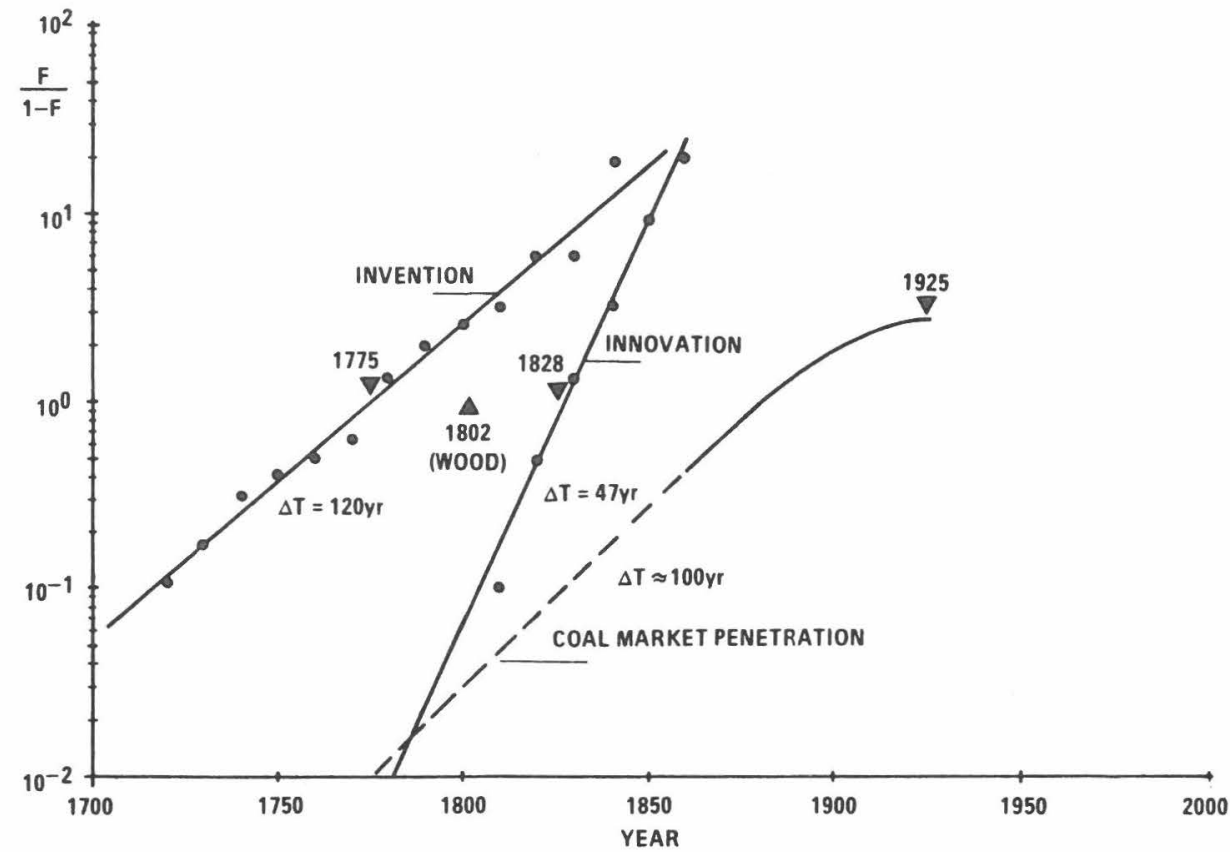

Fig. 7. The 1802 wave. $F$ is here the fraction of total set of basic innovations implemented up to time $t$. This set is made of $\mathbf{2 1}$ items listed in Table $\mathbf{2}$ and further explained for the case of the locomotive. The set of corresponding inventions is displayed in the same way $F(t)$ being the fraction of them discovered up to time $t$. $\Delta T$ denotes the time from $F=0.10$ to $F=0.90$, (i.e., from $10 \%$ to $90 \%$ of the whole set.) 
TABLE 2

The 1802 Cycle

\begin{tabular}{lcc}
\hline & Innovation & Invention \\
\hline Power generator & 1849 & 1820 \\
Electromedical stimulator & 1846 & 1831 \\
Deep sea cable & 1866 & 1847 \\
Electricity production & 1800 & 1708 \\
Insulated conductors & 1820 & 1744 \\
Arc lights & 1844 & 1810 \\
Pedal bicycle & 1839 & 1818 \\
Rolled rails & 1835 & 1773 \\
Rolled wires & 1820 & 1773 \\
Puddling furnace & 1824 & 1783 \\
Blast furnace with coke & 1796 & 1713 \\
Crucible steel & 1811 & 1740 \\
Locomotives & 1824 & 1769 \\
Telegraph & 1833 & 1793 \\
Lead chamber process & 1819 & 1740 \\
Pharmaceutical industries & 1827 & 1771 \\
Quinine industries & 1820 & 1790 \\
Hard rubber & 1852 & 1832 \\
Portland cement & 1824 & 1756 \\
Potassium chloride & 1831 & 1777 \\
Photography & 1838 & 1727 \\
\hline
\end{tabular}

How invention and innovation dates are chosen:

The case of locomotives.

\begin{tabular}{ll}
\hline 1769 & Watt: Low pressure machine \\
1770 & Cugnot: Steam gun vehicle \\
1790 & Read: Steam road vehicle \\
1800 & Watts: Patent on steam engines expires \\
1801 & Trevithick starts work on locomotives \\
1804 & Evans: Road locomotive \\
1811 & Blenkinskop: First toothed gear locomotive \\
1813 & Hadley: Locomotive on rails \\
1814 & Stephenson starts work \\
$\frac{1824}{1825}$ & Stephenson builds first locomotive plant \\
\hline
\end{tabular}

Source: Mensch [10].

be located. The time between the two keeps decreasing along the wave; it will start as large again in the next one, as we shall see. The current idea of a secular reduction of the delay from invention to innovation is certainly false, although more subtle accelerations actually occur.

The 1857 cycle is reported in Figure 8 and Table 3. Topologically it is identical to the previous one. All the time constants are different, however, and shorter: 85 years for inventions and 33 years for innovations, instead of 120 and 47 years, respectively, showing a certain level of acceleration.

The 1920 cycle is reported in Figure 9 and Table 4 with nothing special to report except, again, the excellent fit of the data to the logistic interpolation and a further shortening of the time constants, to 55 years for inventions and only 23 years for innovation. The distance between the centers, too, is reduced-to 32 years, strangely reminiscent of the 33 years of the innovation time constant of the 1857 wave. Incidentally, the 


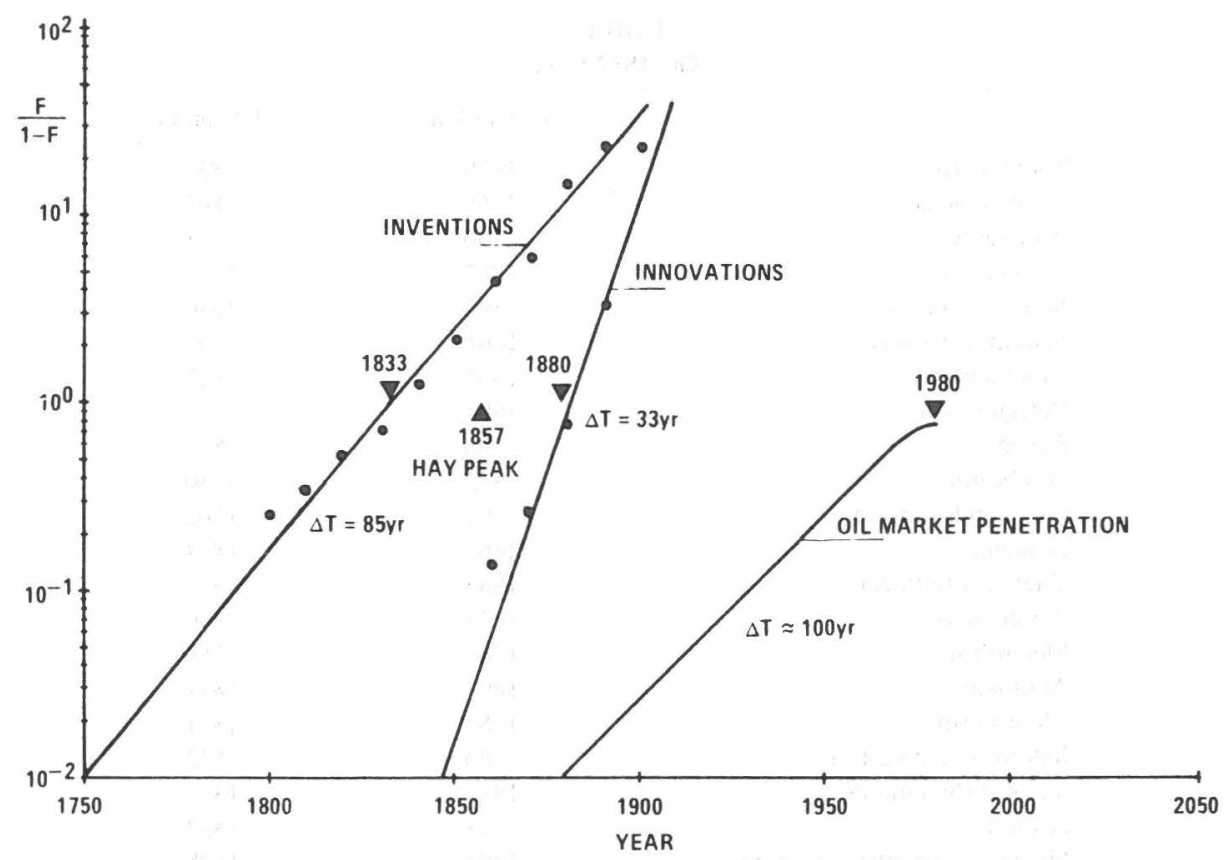

Fig. 8. The 1857 wave, dealt with as the previous one. The set includes 40 items listed in Table 3 .

distance between the centers of this wave is 47 years, which perfectly coincides with the 47 years time constant of the 1802 innovation wave.

These can certainly be coincidences, if improbable, but regularities raise suspicion of clockwork sitting behind the face, and suspicion stimulates curiosity. I therefore put together, in Table 1, the various figures connected to the three waves to see if more suspicious regularities would appear.

They do, in fact. One is that the distance between waves is about 55 years, measured at center points of innovations. This has been observed by Mensch and by Senge, and has been correlated to the Kondratiev cycle, by Mensch as a driving force of the cycle and by Senge as an effect of it.

The time constants of the innovation waves become shorter and they have the constant geometric ratio of roughly 1.42 or $\vee 2$. In the century or so covering the three dashes, the speed has increased by a factor of 2 .

Furthermore, the introduction of new primary energy sources seems to be somehow in tune with the innovation waves, crossing them around the $10^{-2}$ level, and the saturation point for coal in 1923 coincides with the midpoint of the 1921 cycle. I then looked for a saturation point corresponding to the 1880 cycle, and with some difficulty collecting data I found one around 1860 for presteam mechanical power, that is, draw-animals, whose primary source of energy is hay. It sounds a little queer today, but at that time in the United States $80 \%$ of all mechanical power (including sailing ships) was located in draw-animals. 1802 should be the peak or at least a sharp bend for wood fuel, but I have not been able to prove it.

Using all these bits and pieces I tried to reconstruct the characteristics of the next wave. It is certainly better than reading tea leaves, and the fact that various things interlock with a smooth click may be the expression of sound mechanics. 
TABLE 3

The 1857 Cycle

\begin{tabular}{|c|c|c|}
\hline & Innovation & Invention \\
\hline Thomas steel & 1878 & 1855 \\
\hline Safety matches & 1866 & 1805 \\
\hline Aniline dyes & 1860 & 1771 \\
\hline Cooking fat & 1882 & 1811 \\
\hline Indigo synthesis & 1897 & 1880 \\
\hline Sodium carbonate & 1861 & 1791 \\
\hline Aluminum & 1887 & 1827 \\
\hline Refrigeration & 1895 & 1873 \\
\hline Rayon & 1890 & 1857 \\
\hline Gas heating & 1875 & 1780 \\
\hline Oxyacetylene welding & 1892 & 1862 \\
\hline Dynamite & 1867 & 1844 \\
\hline Chemical fertilizer & 1885 & 1840 \\
\hline Preservatives & 1873 & 1839 \\
\hline Electrolysis & 1887 & 1789 \\
\hline Antitoxin & 1894 & 1877 \\
\hline Chloroform & 1884 & 1831 \\
\hline Iodoform (antiseptic) & 1880 & 1822 \\
\hline Veronal (barbiturate) & 1882 & 1862 \\
\hline Aspirin & 1898 & 1853 \\
\hline Phenazone (synthetic painkiller) & 1883 & 1828 \\
\hline Baking powder & 1856 & 1764 \\
\hline Plaster cast & 1852 & 1750 \\
\hline Mass production of sulphuric acid & 1875 & 1819 \\
\hline Synthetic alkaloid (cocaine) & 1885 & 1844 \\
\hline Synthetic alkaloid (chinoline) & 1880 & 1834 \\
\hline High-grade steel & 1856 & 1771 \\
\hline Electrodynamic measurement & 1846 & 1745 \\
\hline Lead battery & 1859 & 1780 \\
\hline Double armature dynamo & 1867 & 1820 \\
\hline Commutator & 1869 & 1833 \\
\hline Cylinder armatured motor & 1872 & 1785 \\
\hline Arc lamp & 1873 & 1802 \\
\hline Incandescent light bulb & 1879 & 1800 \\
\hline Electric locomotive & 1879 & 1841 \\
\hline Electric heating & 1882 & 1859 \\
\hline Cable construction & 1882 & 1820 \\
\hline Telephone & 1881 & 1854 \\
\hline Steam turbine & 1884 & 1842 \\
\hline Water turbine & 1880 & 1824 \\
\hline Transformer & 1885 & 1831 \\
\hline Resistance welding & 1886 & 1841 \\
\hline Arc welding & 1898 & 1849 \\
\hline Induction smelting & 1891 & 1860 \\
\hline Meters & 1888 & 1844 \\
\hline Electric railroad & 1895 & 1879 \\
\hline Long-distance telephoning & 1910 & 1893 \\
\hline High tension insulation & 1910 & 1897 \\
\hline Gasoline motor & 1886 & 1860 \\
\hline
\end{tabular}

Source: Mensch [10]. 


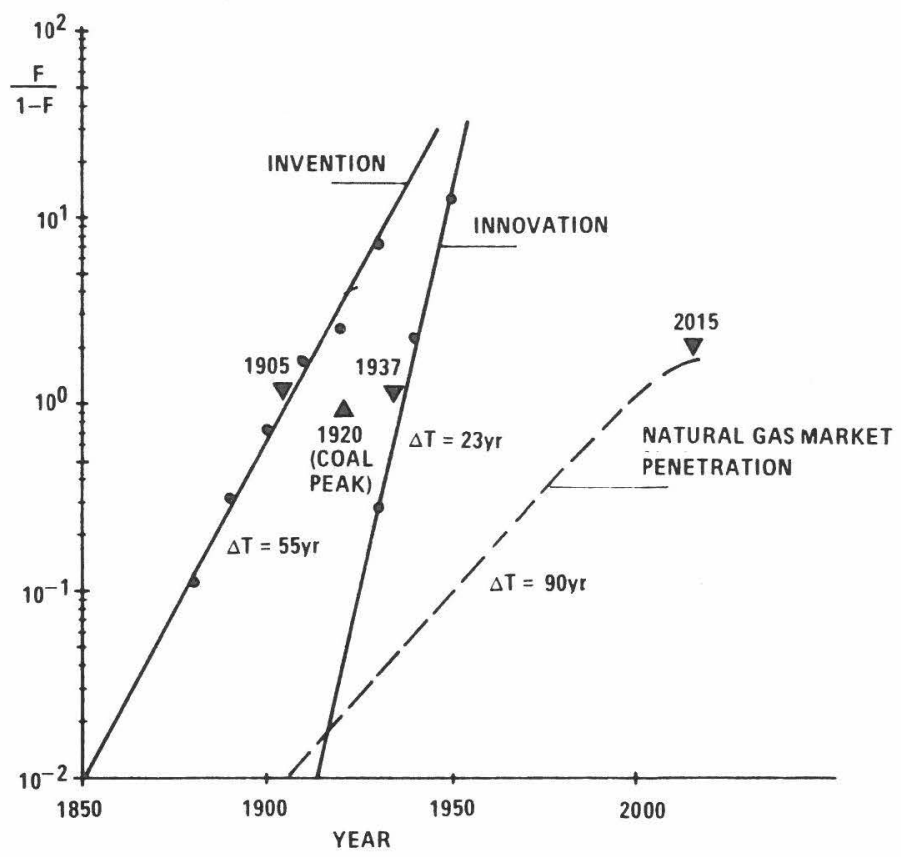

Fig. 9. The 1920 wave, also dealt with as in Figure 7. The set includes 51 items listed in Table 4 .

The exercise, already given in parenthesis in Table 1, is presented graphically in Figure 10. The 55-year cycle gives 1993 as centerpoint for the innovation wave. The time constant of 16 years comes from that of the previous cycle, 23 years, divided by 1.42 . The centerpoint distance is equal to the time constant of the previous cycle, or 23 years, bringing the centerpoint of inventions to 1969-1970. The time constant of inventions is derived from the previous one, 55 years divided by 1.42, which gives 38 years. The midpoint is 1980, which neatly corresponds to the maximum of oil penetration, as shown in Figure 5. Also, the intersection of $1 \%$ of the nuclear energy line and the innovation line matches previous coincidences.

The real starting point of the new wave will be 1984, a date that Orwell made famous in a not very different context, perhaps prophetically. That should also be the end of the recession inside which willy-nilly we are muddling, and in a powerful 16-year dash the world economy should ride the wave again.

As the inventions curve shows, $80 \%$ of the inventions that will go into the next rush are already made in 1980 . We don't really know yet where they are, and everybody can have his guesses. Obvious ones are linked to information management and manipulation, including genetic engineering and the new very sophisticated chemistry, even base chemistry, that can come from that. Less obvious ones are linked to the management of new energy sources, in this special case nuclear energy. As the electrical systems will become saturated with nuclear energy in various countries, precisely at the beginning of the 1990s, technologies to go from nuclear energy to chemicals and synthetic fuels will have a real chance to enter the industrial web. Around that date, too, air traffic will need 
TABLE 4

The 1921 Cycle

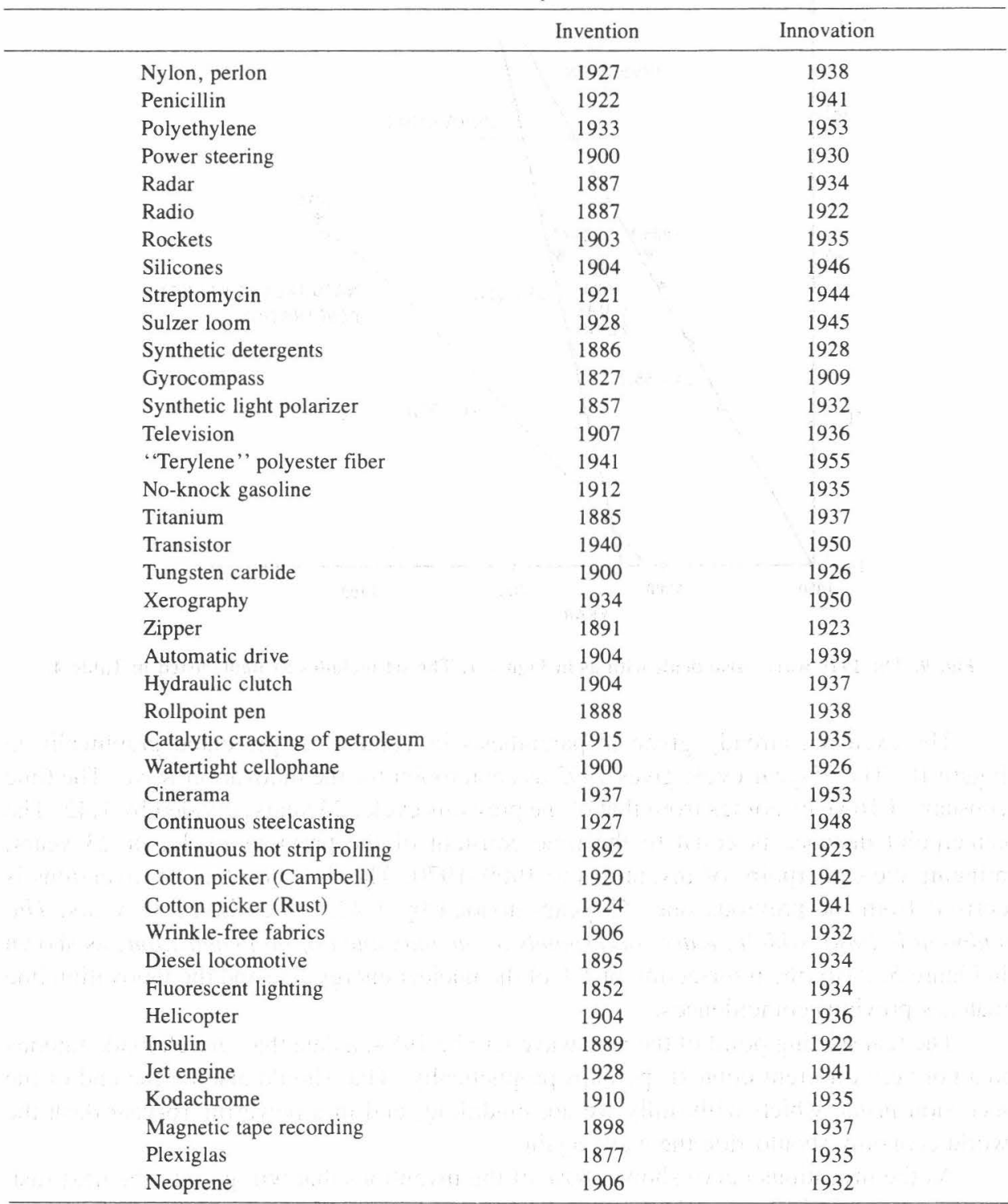

Source: Mensch [4].

performance almost beyond the potential of present technology [12], and a breakthrough is in sight with planes redesigned around the use of liquid hydrogen as a fuel, for example, with cryohypersustentation and hypersonic flight [13]. Cars fueled with $\mathrm{H} 2$ may go into the same niche around the synthetics from nuclear.

In the field of food and agriculture, many innovations are hovering around in search of a sponsor [14]. For some this may be their last chance. The next round is half a century away!

The question of how many innovations will pop up in this cycle can also be answered 


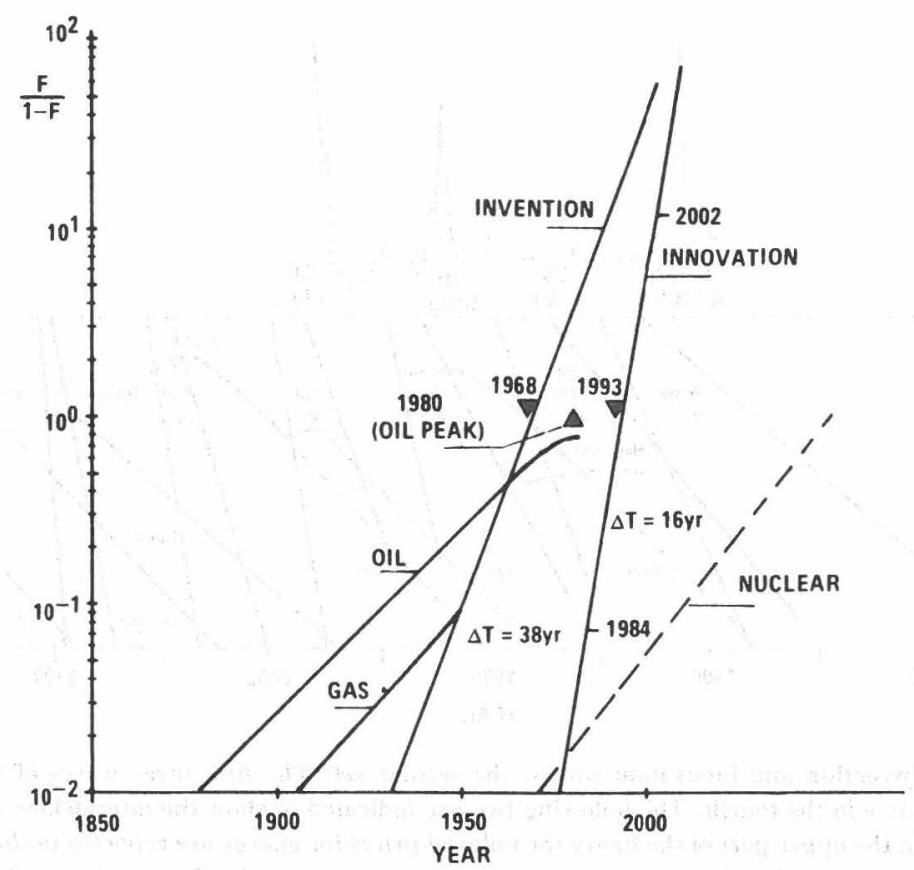

Fig. 10. Using the regularities of the previous three waves, the forthcoming one, the 1980 wave, has been constructed. Although the process has already started, the crucial years appear to be between 1984 and 2000 , when $80 \%$ of the basic innovations will have been introduced. What the innovations are, and how many, is however unknown.

up to a point. The phenomenological equation says that $10 \%$ will be on line in 1984 , so the only thing we have to do is to go out and count them now: The wave will have ten times as many. My personal projection is for the launching of about 100 new industries before the end of the century.

These and other considerations make our round appear very plausible, and so I kept playing the game in a scenario spirit, building the next waves, too. The result of the exercise is reported in the lower part of Figure 11. Posterity may have fun in crosschecking it.

What comes out again makes much sense. The next round of primary energies is required around 2025, which is a safer date than the year 2000 of Figure 5, a date we chose under the pressure of solar and fusion enthusiasts. Back of the envelope calculations show that a sensible and successful course for fusion will give just around $1 \%$ of the market in 2025, but then the peak of natural gas is going to move forward to around 2040, which is precisely what the coincidence with the center of the fifth cycle is asking for. On the other hand, the business as usual rate of penetration for nuclear (100 years time constant) would be confirmed and its saturation in the year 2090, at around $60 \%$ of the market, would match beautifully the sixth cycle.

I took the poetic license of calling the new primary energy associated with that cycle $\mu$-sion, with the argument that scientists tampering with more and more elementary particles, will presumably find a way to squeeze energy out of them. Also possible is solar power beamed from Venus. 


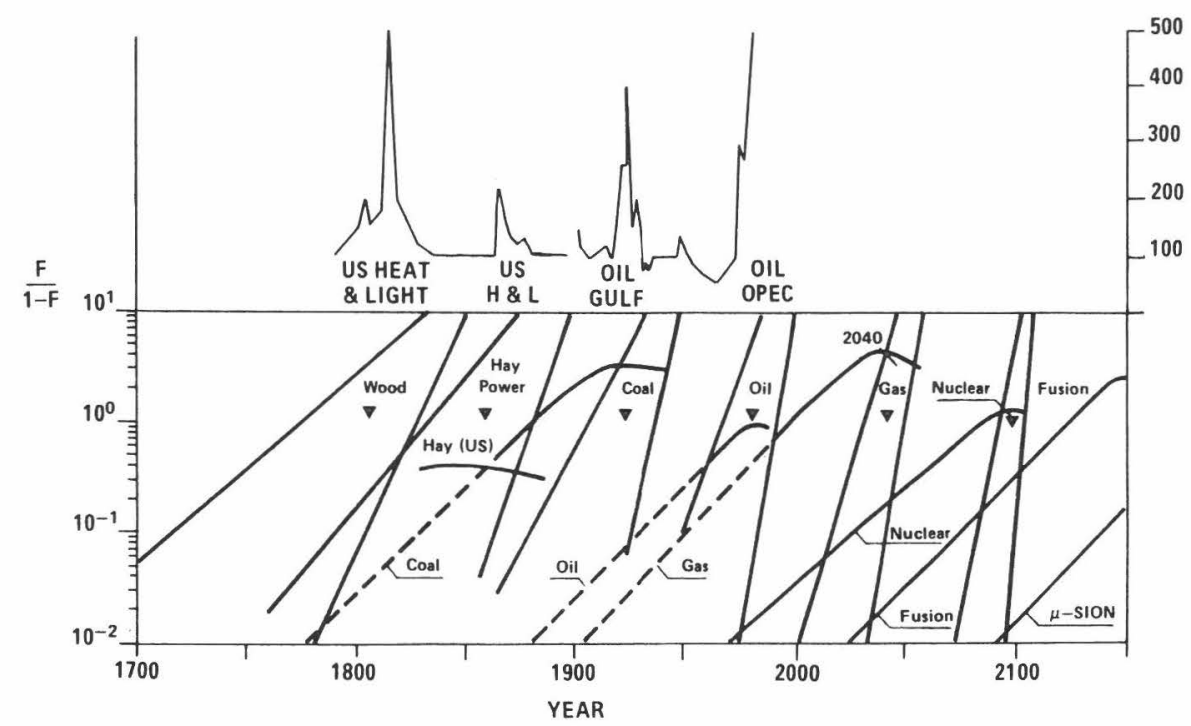

Fig. 11. Invention and innovation waves, the secular set: The first three waves of the series are historical. We live in the fourth. The following two are indicated to show the interlocking of the various components. In the upper part of the figure the indexed prices for energy are reported to show the precise match between energy price flaring and wave centers. By analogy one should expect a rapid fall of the real price for oil in the next few years. Sources: For the U.S. cost index, U.S. Department of Commerce [15]. For the Gulf and OPEC oil cost index, Beijdorff and Lukas [16].

The description of the structure of the energy market in Figure 5 is in physical terms, and the very simple set of logistic equations behind it permits precision forecasting and backcasting over at least 50 years. This means that prices that move around all the time cannot be considered voluntaristic causes, as economists tend to think, but only contextual indicators, as I find it almost inevitable to think. Assuming that prices are effects and the physical structures are causes, I looked for some secular correlations. The indexed price for energy is shown in the upper part of Figure 11. The remarkable fact here is that the prices for energy "flared" in coincidence with the midpoints of the cyclesthree times in the past and now, at the presumed midpoint of the 1980 cycle. This coincidence helps support the method of forecasting I used, the click of another piece falling into place. It also opens the way to the far-reaching speculation that in real terms the price of energy in general and of oil in particular will fall sharply during the next few years.

At this point the canonical questions come in: What are the mechanisms of such regularities, and what determines the length of the period between innovation cycles?

Concerning the first question, I would say that man and societal feedback loops have been the same for many centuries, contrary to our feeling of fast change, and that the concept of a learning society is the heuristic path to a microscopic description in the spirit of the statistical mechanics that came to buttress macroscopic thermodynamics in the physical sciences. It took a century, however, for this very intricate branch of science to come to maturity.

To a physicist's eye, present-day econometric models still look much like toddling 


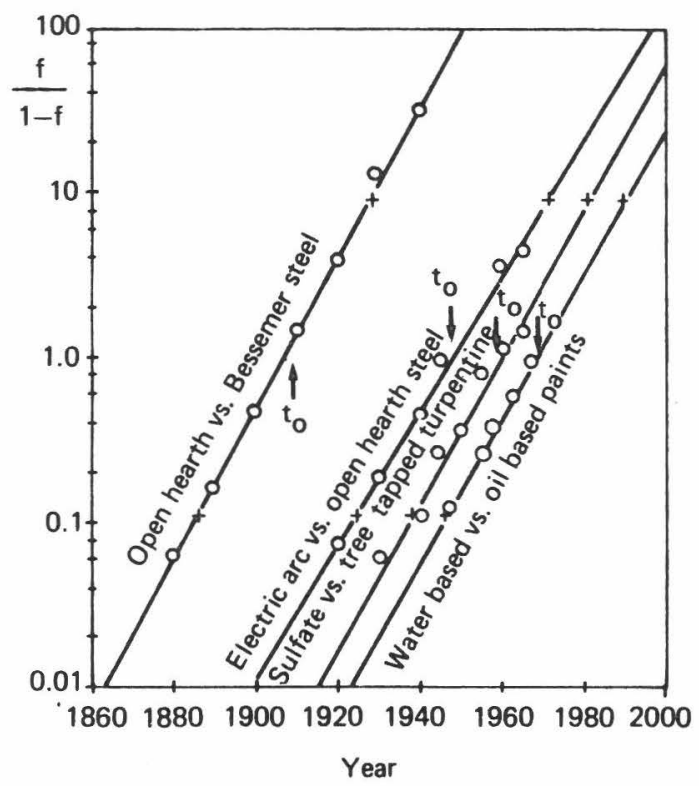

Fig. 12. Market penetration of four processes or machines in the United States. The time constant is about $\mathbf{5 0}$ years for all four cases. Here the process is one way and there are no cycles involved. My presumption is that the rate of these penetration processes is the primary clock of economy. This rate may be closely linked to human behavior and may be the deep reason for the stability of the cycles' length.

and stuttering. What I think most dangerous and misleading is their blind devotion to monetary concepts. All my analysis of economic systems tends to show that monetary variables are the manifestation of a deeper stratum of phenomena, where the real mechanisms lie. The description of the evolution of the energy market in Figure 5 does not require the concept of money at all and beats any econometric model in precision, simplicity, and capacity to forecast.

Concerning the second question, I lean much toward the interpretation that the behavior of the final consumer is the "central clock" of the system. The time constants for market penetration among numerous consumers and for capital products as well [17] (Figure 12) tend to cluster around 50 years. It is a current observation that when a product nears saturation of the market the corresponding industry enters into trouble. Volterra equations for interacting populations show oscillatory behavior [4], while industry probably exhausts its potential for incremental and managerial innovation, thus reducing its capacity to cope with change.

If many industries happen to be born together, they will enter into the embalming stage together, and this will liberate capital for new enterprises. Such a Schumpeterian view gives good hints concerning the self-amplifying mechanism of the waves. The reason why innovation, and even more invention, fit the straightjacket of precise functional relationships remains a deep mystery, however. Societal mechanisms seem capable of switching genius on and off.

The above considerations are not really meant to explain in scientific terms but only to wind up for the next run of analysis. 


\section{Conclusions}

During the last 300 years basic inventions and innovations appear in waves, of precise configuration and frequency, that are substantially isomorphic with a "contraction" of the time scale by roughly a factor of 2 every century. The introduction of new primary energies, their phasing out of the market and their prices appear to be rigidly linked to these cycles, adding another dimension to forecasting in the field of energy systems.

The concept of a learning society, with its implications on the ecological Volterra equations, represents a very powerful tool in organizing social behavior and hints to the possibility of a unified theory for genetic evolution, ecology, sociology, and economics.

\section{References}

1. Marchetti C., and Nakicenovic, N., The Dynamics of Energy Systems and the Logistic Substitution Model, RR-79-13, International Institute for Applied Systems Analysis, Laxenburg, Austria, December 1979.

2. Peterka, V., Macrodynamics of Technological Change: Market Penetration by New Technologies, RR-77-22, International Institute for Applied Systems Analysis, Laxenburg, Austria, November 1977.

3. Fleck, F., RegelmäBigkeiten bei Marktdurchdringungsprozessen alsFolge des individuellen Nachfrageverhaltens. Dissertation, Fakult $+\mathrm{t} t$ für Wirtschaftswissenschaften der Universität Fridericiana Karlsruhe (Technische Hochschule), Karlsruhe, West Germany, 1980.

4. Goel, N.S., Maitra, S.C. and Montroll, E. W., On the VolterranonlinearModels of Interacting Populations.Rev. Mod. Phys. 43, 231 (1971).

5. Bush, R. R. and Mosteller, F., 2Stochastic Models for Learning, Wiley, New York, 1955.

6. Whiston, T. G., Life is Logarithmic, inAdvances in Cybernetics and Systems (J. Rose, ed.), Gordon and Breach, London, 1974.

7. The World Almanac, Doubleday, 1971.

8. Marchetti, C., Energy Systems - The Broader Context, Technol. Forecast. Soc. Change 14, 191-203 (1979).

9. Marchetti, C., Primary Energy Substitution Models, Technol. Forecast. Soc. Change 10, 350 (1977).

10. Mensch, G.,Dastechnologische Patt, Umschau Verlag, Frankfurt/Main, 1975; for details on how the data have been selected, the German edition is preferable to the English edition, Stalemate in Technology, Ballinger, Cambridge, Mass., 1979. These books are also recommended for a good bibliography on research on the innovation process.

11. Graham, A. K., and Senge, P. M., A Long-Wave Hypothesis on Innovation, workshop on National Innovation Policy and Firm Strategy, December 1979, International Institute for Applied Systems Analysis, Laxenburg, Austria; also Technol. Forecast. Soc. Change 17, 283-311 (1980).

12. Marchetti, C., The Evolution of the Energy Systems and the Aircraft Industry, Proceedings of the Symposium on Hydrogen in AirTransportation, 11-14September 1979, DF VLR Deutsche Forschungs-und Versuchsanstalt für Luft- und Raumfahrt e.V. Stuttgart, F.R.G.

13. Brewer, G. D.,Characteristics of Liquid Hydrogen Fueled Aircraft, Proceedings of the Symposium Hydrogen in Air Transportation, 11-14 September 1979, DF VLR Deutsche Forschungs- und Versuchsanstalt für Luft- und Raumfahrt e. V., Stuttgart, F.R.G.

14. Marchetti, C., On Energy and Agriculture: From Hunting-Gathering to Landless Farming, RR-79-10, International Institute for Applied Systems Analysis, Laxenburg, Austria, December 1979.

15. Historical Statistics of the United States, U.S. Department of Commerce, Washington, D.C., 1975.

16. Beijdorff, A. F., and Lukas, J. H., Energy Price: Pervasive Carrier of Information, Group Planning Shell Internation Petroleum Company, Shell Centre, London.

17. Fisher, J.C., andPry, R. H., A SimpleSubstitution Model of TechnologicalChange, 70-C-215, General Electric Company, Research and Development Center, Schenectady, N. Y., Technical Information Series, 1970; see also Technol. Forecast. Soc. Change 3, 75-88 (1971). 